http://dx.doi.org/10.5007/2175-7968.2013v1n31p155

\title{
ENSINO SUPERIOR POLITÉCNICO DA TRADUÇÃO EM MACAU
}

\author{
Lurdes Escaleira \\ Instituto Politécnico de Macau \\ lescaleira@ipm.edu.mo \\ Rosa Bizarro \\ Universidade do Porto/Portugal \\ rosabizarro55@gmail.com
}

\begin{abstract}
Resumo: O presente artigo tem como objetivo refletir sobre o ensino/ aprendizagem da Tradução Chinês/Português, em Macau, e o papel que o ensino superior politécnico tem desempenhado na formação de tradutores. Macau vive, desde há mais de quatro séculos, sob o signo do contacto intercultural e interlinguístico em que o Português e o Chinês, hoje línguas oficiais, têm convivido e obrigado a um esforço de tradução, assumindo-se, atualmente, como uma plataforma importante do diálogo entre a República Popular da China e os Países de Língua Portuguesa. Apesar de várias tentativas, só em 1991 é criado o ensino superior público de Macau e o curso de Tradução, tendo a formação de tradutores, com mais de um século de história, estado, até essa data, a cargo de um departamento governamental. Em conformidade, iremos abordar as várias propostas curriculares que têm vindo a ser implementadas no Instituto Politécnico de Macau com o objetivo de formar tradutores que sirvam de "intermediários" entre as línguas e as culturas distintas, Portuguesa e Chinesa, que estão presentes no quotidiano de Macau e cujo campo de influência se tem vindo a alargar, atendendo ao aumento significativo da procura de tradutores/intérpretes devidamente preparados.
\end{abstract}

Palavras-chave: tradução, tradutor, ensino superior, currículo, língua, cultura. 


\title{
TRANSLATION TEACHING IN MACAO'S POLYTECHNIC EDUCATION
}

\begin{abstract}
This article "Translation teaching in Higher Education in Macau at the Polytechnic" aims to discuss the issues around teaching and learning of Chinese / Portuguese Translation in Macau, and the role played by the Macau Polytechnic Institute in translators training. For more than four centuries, Macau has been a place of intercultural contact where the Portuguese and the Chinese, now the current official languages, have coexisted and implied constant translation efforts; today, Macau is seen as an important platform between the People's Republic of China and Portuguese Speaking Countries, which has stressed the importance of translation professionals. Despite several attempts, Macau's public higher education was only established in 1991, as well as a translation degree program; until then, and for more than a century, the translators training was held by a government department. We will discuss several curricular structures implemented over the years in the Macao Polytechnic Institute for training translators who can intermediate between Chinese and Portuguese languages and cultures growingly expanding in Macau, given the significant increase in the demand for properly trained translators/interpreters.

Keywords: translation, translator, higher education, curricula, language, culture.
\end{abstract}

\section{Introdução}

Ao longo da história da humanidade, a Tradução tem desempenhado um papel fulcral na comunicação entre pessoas, bem como facilitado a prática de inúmeras atividades e o ensino de diferentes matérias. Isto é particularmente visível em Macau, um pequeno território situado na Ásia que, durante mais de quatro séculos, foi administrado por Portugal e que é, desde 20 de dezembro de 1999, uma Região Administrativa Especial da República Popular da China. Nesse espaço, estamos perante um caso paradigmático de presença simultânea de várias línguas e culturas, com destaque para o Chinês (com predominância do Cantonês falado) e o Português, 
sem, no entanto, ter jamais existido uma política de incremento do bilinguismo que tivesse levado a maioria da população a dominar, a nível escrito e oral, ambas as línguas.

Desde os primórdios da administração portuguesa que a Tradução se assumiu, assim, como atividade fulcral na vida do território e a necessidade de comunicar, em duas línguas, com estruturas lógica e gramatical diferentes, obrigou a um esforço, por parte do Governo de Macau, de formação de um corpo de intérpretes-tradutores que pudessem assegurar a comunicação entre administradores e administrados e, ainda, com os poderes políticos e os agentes comerciais do Império do Meio.

Indispensável para o funcionamento da sociedade de Macau, o ensino da Tradução reveste-se de especificidades próprias e desenvolve-se numa história construída ao longo de mais de um século.

A primeira tentativa de estabelecimento de uma escola de intérpretes-tradutores pertenceu ao Governo, o qual tinha como objetivo satisfazer as suas próprias necessidades. No entanto, o ensino superior da tradução só teve início em 1992, após a criação, em 1991, do ensino superior público moderno.

No presente artigo, referiremos o percurso feito até à criação do ensino superior da Tradução em Macau e apresentamos as propostas curriculares, desenvolvidas no ensino superior politécnico, de formação de profissionais do ato de traduzir.

\section{Antecedentes Históricos}

A análise da formação de tradutores, em Macau, permite-nos estabelecer três fases distintas: (1) pré-ensino da Tradução; (2) ensino formal não superior da Tradução e (3) ensino superior politécnico da Tradução.

Na primeira fase, situam-se as tentativas de implementação do ensino superior, através do Colégio Universitário de S. Paulo, do Seminário Diocesano de S. José e da Universidade Internacional de Macau. 
Nos dois primeiros casos, a Igreja faz a primeira tentativa de estabelecimento de um ensino superior no qual insere o estudo das línguas (Português, Latim, Chinês e Gramática). Embora não haja, de forma explícita, uma formação em Tradução, há, contudo, registos que dão conta que os missionários se dedicaram ao ensino das línguas, à tradução de obras ocidentais para as línguas orientais e vice-versa e à criação de glossários (Santos, 1994).

A Universidade Internacional de Macau, Decreto-Lei $\mathrm{n}^{\circ}$ 11/80/M, projeto apoiado pelo Governo, para além de outros objetivos, contemplava a divulgação e expansão da língua, cultura e ciência portuguesas e o estudo da Diáspora Portuguesa no Oriente.

Estes projetos foram, porém, inviabilizados e só no séc. XX, em 1981, devido à iniciativa de um grupo privado de Hong Kong, Macau voltou a ter uma universidade - Universidade da Ásia Oriental - virada para as necessidades de Hong Kong, que, pese embora o esforço desenvolvido, não captou a juventude de Macau.

A segunda fase carateriza-se pela iniciativa governamental que, face à necessidade crescente de tradutores, decide criar, em 1865, dentro da própria estrutura administrativa, o Corpo de Intérpretes/ Tradutores. Estava-se perante uma prática de formação em que os alunos aprendiam no exercício da profissão e eram supervisionados por tradutores experientes, não existindo, contudo, dados que nos permitam afirmar tratar-se de uma escola propriamente dita.

Em 1905, pelo Decreto Régio de 22 de Julho, é criada uma Escola, na dependência da Repartição do Expediente Sínico, para habilitar intérpretes sinólogos e funcionários públicos. Os cursos - Intérprete-Tradutor de $2^{\mathrm{a}}$ classe (5 anos) e de $1^{\mathrm{a}}$ classe ( 2 anos) - incidiam no estudo das Línguas Sínica escrita, Cantonês e Pequinense falado e em estudos acessórios (Geografia, História, Política, Filosofia confuciana e pós-confuciana, relações da China com as potências ocidentais e Etiqueta e ritos da China).

As convulsões das I e II Guerras Mundiais refletiram-se na Escola que, a partir de 1944, deixa de atrair alunos, verificando-se um interregno de 17 anos. O clima pós- Guerra traz um novo im- 
pulso: alteram-se os regulamentos da Escola, o curso de Intérprete-Tradutor de $2^{\text {a }}$ classe passa para 4 anos, registam-se ligeiras alterações curriculares e aceitam-se alunos externos, regidos por um estatuto próprio (Diploma Legislativo $n^{0}$ 928, Maio de 1946).

Posteriormente, perante a falta de tradutores, o Governo, pelo Decreto-Lei no 47/76/M, determina que "[d]ependente da Repartição dos Serviços de Assuntos Chineses, funciona a Escola Técnica , a qual se destina fundamentalmente a habilitar indivíduos para o seu quadro de intérpretes-tradutores". São ministrados três cursos e o currículo assenta no estudo das línguas de trabalho e numa forte componente prática que permite adquirir um saber fazer que facilitaria a inserção na atividade profissional.

Apesar dos esforços desenvolvidos, não se conseguia acompanhar o ritmo progressivo das exigências do mercado e lutava-se com a falta de instalações, de pessoal docente, especialmente de Português, e com a dificuldade de conciliação de horários de trabalho e de aulas. Neste contexto, a Comissão para a Implementação da Língua Chinesa considera a formação "muito prolongada (...)" sendo necessária "uma reforma que conduzirá à redução de quatro para dois anos e meio do primeiro curso para intérpretes-tradutores" (Alves, 2003: 320-321).

Assim, em 1986, pela Portaria $\mathrm{n}^{\circ}$ 183/86/M, o Governo decide “(...) redimensionar a sua Escola Técnica, que se encontra manifestamente desajustada quer relativamente às orientações pedagógicas atuais e às exigências de uma moderna gestão escolar, quer face às necessidades do Território (...)". Defende que é necessário dotá-la com “(...) novos cursos, de uma estrutura mais adequada à formação do pessoal que seja capaz de dar resposta às exigências (...)" (ibidem), isto é, que prepare tradutores, em quantidade e diversidade de matérias, para enfrentar os desafios colocados pela Transferência de Soberania, permanência da Língua Portuguesa como língua oficial e vigência do Direito de matriz portuguesa.

São, então, criados dois cursos de Tradução: (1) curso básico, três anos e estágio profissionalizante de três meses; (2) curso inten- 
sivo, um ano e estágio profissionalizante de três meses, a funcionar apenas em casos excecionais, destina-se a formar pessoal qualificado para ingresso nos graus 1 e 3 da carreira de Intérprete/Tradutor. O currículo pressupunha um prévio conhecimento de ambas as línguas de tabalho e incidia nas Línguas, Cultura e Tradução. Estava estruturado de acordo com o sistema de ensino frequentado no ensino secundário.

A terceira fase insere-se no novo contexto sócio-político iniciado com a assinatura, em 1987, da Declaração Conjunta Sino-portuguesa. Na altura, não existia nenhuma instituição pública de ensino superior e o Governo, em 1988, optou pela aquisição da Universidade da Ásia Oriental, que, após um processo de reestruturação, em 1991, adquire o estatuto de universidade pública. Nesse ano, é, também, criado o ensino superior politécnico que integrou as escolas que estavam na dependência de serviços públicos, por exemplo, em 1992, a Escola Técnica foi transferida para a Escola de Línguas e Tradução.

Durante este período de transição, ainda na Universidade da Ásia Oriental, foi criada, através da Portaria no 272/93/M, a Licenciatura em Tradução/Interpretação (extinta em 1997), de quatro anos, com um currículo que assentava nas línguas de trabalho, no Inglês, nas Técnicas de Tradução, noções de áreas específicas (Economia, Finanças, Direito e Adminstração Pública no contexto de Macau) e prática de Tradução/Interpretação.

Estão, assim, criadas as condições para o estabelecimento do ensino superior politécnico da Tradução o qual, ao longo das duas últimas décadas, tem sofrido várias reformas, que têm como objetivo formar profissionais preparados para o mercado global da tradução Chinês/Português.

\section{Ensino Superior Politécnico Da Tradução}

O ensino politécnico da Tradução, na vertente Tradução/Interpretação -Chinês/Português, pode dividir-se em duas fases: (1) 
criação da ESLT, transferência da Escola Técnica da Direcção dos Assuntos Chineses para o Instituto Politécnico de Macau e ensino caraterizado por uma "repartição" entre a Universidade de Macau e o Instituto Politécnico e (2) formação superior em Tradução/ Interpretação no Instituto Politécnico de Macau.

\subsection{Primeira Fase}

Em 1992, pelo Decreto-Lei no. 16/92/M, é criada a Escola de Línguas e Tradução a quem compete a formação de “(...) quadros com elevado nível de exigência qualitativa nos aspetos cultural, científico, técnico e profissional". Simultaneamente, é extinta a Escola Técnica e são transferidas as suas competências e atribuições para a Escola de Língus e Tradução por se considerar que “(...) $a$ formação de intérpretes-tradutores (...) pode ser alcançada, com objetivos mais amplos e qualitativamente mais exigentes, pelo Instituto Politécnico de Macau”.

Nesta fase, deu-se continuidade aos programas, iniciados no âmbito da Escola Técnica e, pela Portaria 100/94/M, são criados no Instituto Politécnico “(...) os seguintes cursos que conferem o grau de bacharel: Curso de Tradução/Interpretação; Curso Complementar de Tradução/Interpretação destinado a facultar o acesso ao grau de bacharel aos graduados pelos Cursos Básico e Intensivo da Escola Técnica".

Estamos, pois, perante o primeiro currículo de um curso do ensino superior politécnico, visto os anteriormente ministrados serem apenas de conclusão dos estudos já iniciados na Escola Técnica.

O bacharelato em Tradução/Interpretação-Chinês-Português, de três anos, teve início no ano letivo de 1993/94 e contemplava as propostas curriculares adaptadas ao sistema de ensino de proveniência dos alunos ${ }^{1}$. Aliás, esta continua a ser uma prática adotada e, ainda hoje, existem duas variantes do currículo para alunos provenientes do sistema de ensino: (1) Português e (2) Chinês ou Inglês. 
Quadro 1- Bacharelato em Tradução/Interpretação (Sistema de Ensino Português)

\begin{tabular}{|c|c|c|c|c|}
\hline Ano & Disciplinas & Tipo & $\begin{array}{l}\text { Crédi- } \\
\text { tos }\end{array}$ & $\begin{array}{l}\text { Horas/ } \\
\text { Sema- } \\
\text { nais }\end{array}$ \\
\hline एँ & $\begin{array}{l}\text { Língua Chinesa I/ II } \\
\text { Mandarim I } \\
\text { Língua e Literatura Portuguesa I/II } \\
\text { Linguística Portuguesa I/II } \\
\text { História de Macau } \\
\text { Introdução à Informática } \\
\text { Prática de Informática }\end{array}$ & $\begin{array}{l}\text { Sem. } \\
\text { Anual } \\
\text { Sem. } \\
\text { Sem. } \\
\text { Anual } \\
\text { Sem. } \\
\text { Sem. }\end{array}$ & $\begin{array}{l}10 / 10 \\
10 \\
6 / 6 \\
3 / 3 \\
6 \\
3 \\
3\end{array}$ & $\begin{array}{l}10 / 10 \\
5 \\
6 / 6 \\
3 / 3 \\
3 \\
3 \\
3\end{array}$ \\
\hline $\begin{array}{l}\text { No } \\
\text { 菏 }\end{array}$ & $\begin{array}{l}\text { Língua Chinesa III/IV } \\
\text { Chinês Moderno I/II } \\
\text { Mandarim III } \\
\text { Análise de Textos da Literatura PT } \\
\text { Contemporânea I/II } \\
\text { Cultura Portuguesa I } \\
\text { Prática de Tradução } \\
\text { Prática Política e Administrativa de } \\
\text { Macau } \\
\text { Cultura Portuguesa II }\end{array}$ & $\begin{array}{l}\text { Sem. } \\
\text { Sem. } \\
\text { Anual } \\
\text { Sem. } \\
\text { Sem. } \\
\text { Sem. } \\
\text { Sem. } \\
\text { Sem. }\end{array}$ & $\begin{array}{l}9 / 8 \\
2 / 2 \\
10 \\
6 / 4 \\
3 \\
2 / 2 \\
3 \\
3\end{array}$ & $\begin{array}{l}9 / 8 \\
2 / 2 \\
5 \\
6 / 4 \\
3 \\
2 / 2 \\
3 \\
3\end{array}$ \\
\hline $\begin{array}{l}w \\
0 \\
\vec{z} \\
0\end{array}$ & $\begin{array}{l}\text { Língua Chinesa V/VI } \\
\text { Chinês Moderno III } \\
\text { Mandarim III } \\
\text { Cultura Chinesa } \\
\text { Análise de Textos da Literatura PT } \\
\text { Contemporânea III/ IV } \\
\text { Introdução ao Estudo do Direito I /II } \\
\text { Teoria e Prática da Tradução } \\
\text { Prática da Interpretação } \\
\text { História Concisa das Relações da China } \\
\text { com o Ocidente }\end{array}$ & $\begin{array}{l}\text { Sem. } \\
\text { Sem. } \\
\text { Anual } \\
\text { Anual } \\
\text { Sem. } \\
\text { Sem. } \\
\text { Anual } \\
\text { Anual } \\
\text { Sem. }\end{array}$ & $\begin{array}{l}7 / 6 \\
2 \\
6 \\
6 \\
3 / 3 \\
3 / 3 \\
6 \\
6 \\
3\end{array}$ & $\begin{array}{l}7 / 6 \\
2 \\
3 \\
3 \\
3 / 3 \\
3 / 3 \\
3 \\
3 \\
3\end{array}$ \\
\hline
\end{tabular}

A análise do plano de estudos para os alunos dos sistemas de ensino Chinês e Inglês permite-nos verificar as adaptações introduzidas. 
Quadro 2 - Bacharelato em Tradução/Interpretação (Sistemas de Ensino Chinês/Inglês)

\begin{tabular}{|c|c|c|c|c|}
\hline Ano & Disciplinas & Tipo & Créditos & $\begin{array}{l}\text { Horas/ } \\
\text { Sema- } \\
\text { nais }\end{array}$ \\
\hline $\begin{array}{l}\overrightarrow{0} \\
2 \\
0\end{array}$ & $\begin{array}{l}\text { Língua Portuguesa I/II } \\
\text { Chinês Moderno I/II } \\
\text { Língua e Literatura Chinesa I/II } \\
\text { Mandarim I } \\
\text { Introdução à Informática } \\
\text { Prática de Informática }\end{array}$ & $\begin{array}{l}\text { Sem. } \\
\text { Anual } \\
\text { Sem. } \\
\text { Anual } \\
\text { Sem. } \\
\text { Sem. }\end{array}$ & $\begin{array}{l}15 / 15 \\
4 \\
6 / 6 \\
8 \\
3 \\
3\end{array}$ & $\begin{array}{l}15 / 15 \\
2 \\
6 / 6 \\
4 \\
3 \\
3\end{array}$ \\
\hline $\begin{array}{l}N \\
0 \\
Z\end{array}$ & $\begin{array}{l}\text { Língua Portuguesa III/IV } \\
\text { Gramática Portuguesa I/II } \\
\text { Conversação em Português I/II } \\
\text { Análise de Textos da Literatura } \\
\text { Clássica, Moderna e Contemporâ- } \\
\text { nea Chinesa I } \\
\text { Mandarim II } \\
\text { Cultura Chinesa } \\
\text { Prática da Tradução }\end{array}$ & $\begin{array}{l}\text { Sem. } \\
\text { Sem. } \\
\text { Sem. } \\
\text { Anual } \\
\\
\text { Anual } \\
\text { Anual } \\
\text { Anual }\end{array}$ & $\begin{array}{l}9 / 6 \\
3 / 3 \\
3 / 3 \\
8 \\
\\
6 \\
6 \\
4\end{array}$ & $\begin{array}{l}9 / 6 \\
3 / 3 \\
3 / 3 \\
4\end{array}$ \\
\hline $\begin{array}{l}w \\
0 \\
己 \\
z\end{array}$ & $\begin{array}{l}\text { Análise de Textos da Literatura PT } \\
\text { Contemporânea I/II } \\
\text { Linguística Portuguesa I } \\
\text { Cultura Portuguesa II } \\
\text { Análise de Textos da Literatura } \\
\text { Clássica, Moderna e Contemporâ- } \\
\text { nea Chinesa I } \\
\text { História de Macau } \\
\text { Introdução ao Estudo do Direito I/II } \\
\text { Teoria e Prática da Tradução } \\
\text { Prática da Interpretação } \\
\text { História Concisa das Relações da } \\
\text { China com o Ocidente }\end{array}$ & $\begin{array}{l}\text { Sem. } \\
\text { Sem. } \\
\text { Sem. } \\
\text { Anual } \\
\\
\text { Anual } \\
\text { Sem. } \\
\text { Anual } \\
\text { Anual } \\
\text { Sem. }\end{array}$ & $\begin{array}{l}6 \\
3 / 3 \\
3 \\
6 \\
3\end{array}$ & $\begin{array}{l}3 \\
3 / 3 \\
3 \\
3 \\
3\end{array}$ \\
\hline
\end{tabular}

Como se pode verificar, existe um total paralelismo e um maior ênfoque na língua de trabalho estrangeira. A falta de candidatos 
tem obrigado a admitir alunos com um conhecimento fraco ou quase nulo da língua de trabalho estrangeira o que, por um lado, exige um desenho curricular que supere estas deficiências e, por outro, causa constrangimentos que afetam tanto alunos como docentes.

Para além da conclusão dos cursos e para dar cumprimento ao estipulado na lei, procedeu-se à criação de novos cursos que tinham como objetivos atrair novos candidatos e habilitar os diplomados pela Escola Técnica com uma formação de nível superior.

O Curso Complementar de Traduçãoo/Interpretação, através da Portaria 100/94/M, destinava-se a “(...) facultar o acesso ao grau de bacharel aos graduados pelos Cursos Básico e Intensivo da Escola Técnica (...)".

Quadro 3 - Curso Complementar de Tradução/Interpretação (alunos do Sistema de Ensino Português)

\begin{tabular}{|c|c|c|c|c|}
\hline Ano & Disciplinas & Tipo & Créditos & $\begin{array}{l}\text { Horas/ } \\
\text { Sema- } \\
\text { nais }\end{array}$ \\
\hline 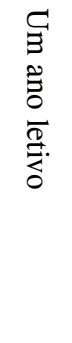 & $\begin{array}{l}\text { Análise de Textos da Literatura } \\
\text { Moderna e Contemporânea Portu- } \\
\text { guesa I/II } \\
\text { Língua Chinesa IV } \\
\text { Mandarim } \\
\text { Teoria e Prática de Tradução } \\
\text { Teoria e Prática de Interpretação } \\
\text { História Concisa das Relações da } \\
\text { China com o Ocidente }\end{array}$ & $\begin{array}{l}\text { Sem. } \\
\text { Anual } \\
\text { Anual } \\
\text { Anual } \\
\text { Anual } \\
\text { Sem. }\end{array}$ & $\begin{array}{l}12 \\
6 \\
6 \\
4 \\
3\end{array}$ & $\begin{array}{l}6 \\
3 \\
3 \\
2 \\
3\end{array}$ \\
\hline
\end{tabular}

$\mathrm{Na}$ proposta curricular apresentada deteta-se uma forte componente linguística, com reforço do ensino do Chinês/Mandarim e da teoria e da prática da Tradução e Interpretação e uma breve abordagem das relações entre a China e o Ocidente. 
Quadro 4 - Curso Complementar de Tradução/Interpretação (Sistema de Ensino Chinês/Inglês)

\begin{tabular}{|c|c|c|c|c|}
\hline Ano & Disciplinas & Tipo & Créditos & $\begin{array}{l}\text { Horas/ } \\
\text { Sema- } \\
\text { nais }\end{array}$ \\
\hline 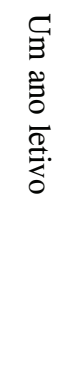 & $\begin{array}{l}\text { Análise de Textos da Literatura } \\
\text { Moderna e Contemporânea Portu- } \\
\text { guesa I/II } \\
\text { Linguística Portuguesa III } \\
\text { Cultura Chinesa } \\
\text { Mandarim } \\
\text { Teoria e Prática de Tradução } \\
\text { Teoria e Prática de Interpretação } \\
\text { História Concisa das Relações da } \\
\text { China com o Ocidente }\end{array}$ & $\begin{array}{l}\text { Sem. } \\
\text { Anual } \\
\text { Sem. } \\
\text { Anual } \\
\text { Anual } \\
\text { Anual } \\
\text { Sem. }\end{array}$ & $\begin{array}{l}6 \\
3 \\
6 \\
6 \\
4 \\
3\end{array}$ & $\begin{array}{l}6 \\
3 \\
3 \\
3 \\
2 \\
3\end{array}$ \\
\hline
\end{tabular}

Nesta altura, o Instituto Politécnico apenas podia ministrar cursos de bacharelato, pelo que foi criado na Universidade de Macau, pela Portaria ${ }^{\circ}$ 89/95/M, o Curso de Complemento que tinha como objetivos desenvolver uma formação cada vez mais especializada e possibilitar aos bacharéis em Tradução/Interpretação do Politécnico a obtenção do grau de licenciatura.

Quadro 5 - Curso de Complemento de Tradução/Interpretação Português/Chinês (Univ. de Macau)

\begin{tabular}{|l|l|l|l|}
\hline Sistema de ensino PT & Sistema de ensino CH/ING & \multicolumn{2}{|l|}{$\begin{array}{l}\text { Horas/ } \\
\text { semanais }\end{array}$} \\
\hline Português Avançado & Português Aplicado & 3 & 6 \\
\hline $\begin{array}{l}\text { Técnicas Composição } \\
\text { do Port. }\end{array}$ & $\begin{array}{l}\text { Técnicas Composição } \\
\text { do Port. }\end{array}$ & 3 & 3 \\
\hline Prática de Tradução I/II & Prática de Tradução I/II & 6 & 3 \\
\hline Prática de Interpretação I/II & Prática de Interpretação I/II & 6 & 6 \\
\hline
\end{tabular}




\begin{tabular}{|c|c|c|c|}
\hline Chinês Escrito Intensivo I/II & Português Intensivo I/II & 12 & 6 \\
\hline Cultura Portuguesa & Cultura Portuguesa & 3 & 6 \\
\hline Cultura Chinesa & Cultura Chinesa & 3 & 3 \\
\hline Gramática Chinesa Moderna & Gramática Chinesa Moderna & 3 & 3 \\
\hline ---------------------------------------- & Chinês Aplicado I/II & ---- & 3 \\
\hline Total & & 39 & 39 \\
\hline
\end{tabular}

Com a duração de dois semestres, o currículo proposto segue a estrutura praticada no Instituto Politécnico no curso de bacharelato, é desenhado de forma flexível, de acordo com os vários sistemas de ensino, e, como a maioria dos alunos eram tradutores em exercício, funcionava em horário noturno.

Com uma forte componente das Línguas (com o reforço do Português ou do Chinês) e das Técnicas e Teorias da Tradução, segue uma estrutura curricular de disciplinas obrigatórias, não existindo qualquer diferenciação na formação de intérpretes e de tradutores.

Os novos programas contemplam, de forma geral, as áreas dos planos de estudo da Escola Técnica; no entanto, a componente prática passou a restringir-se à sala de aula e o estágio profissional deixa de figurar nos currículos. Deu-se uma academização da formação e, aos poucos, o estágio profissional e a obrigatoriedade de prestar serviço, durante o curso, deixam de constar da oferta curricular ${ }^{2}$.

Em nosso entender, encerra aqui o ciclo que corresponde à primeira fase do ensino superior da Tradução em Macau, a qual foi caraterizada por medidas de transição que tiveram como principais objetivos, por um lado, a elevação das qualificações dos Intérpretes/Tradutores já em exercício ou dos alunos que tinham iniciado os seus estudos na Escola Técnica e, por outro, a implementação de um novo currículo que formasse profissionais com elevadas competências profissionais. 
Se pretendermos traçar o percurso académico dos Intérpretes/ Tradutores formados em Macau, até ao final desta fase, vemos que a obtenção da licenciatura implicava a frequência de três instituições de ensino, ou seja, os alunos que tinham obtido ou iniciado a formação na Escola Técnica, concluiram o bacharelato no Instituto Politécnico e, finalmente, frequentaram a Universidade de Macau.

Nesta primeira fase, estamos perante uma formação ministrada pelas duas instituições públicas de ensino superior que tiveram a missão de elevar as qualificações dos tradutores habilitados pela Escola Técnica. Com um forte apoio governamental, isenção de propinas e facilidades de dispensa de serviço para frequência do curso, poucos terão sido os tradutores que não aproveitaram esta oportunidade de obter o grau de licenciatura.

\subsection{Segunda Fase}

Após um período de formação intensiva dos tradutores em exercício, foi possível desenvolver o ensino da Tradução a cargo do ensino politécnico.

$\mathrm{O}$ acesso ao curso de bacharelato passou a fazer-se entre os indivíduos detentores de habilitação académica equivalente ao $11^{\circ}$ ano do sistema de ensino Português, ou equivalente, dos ensinos Chinês ou Inglês ou entre indivíduos maiores de 25 anos aprovados em exame ad-hoc. Os candidatos são submetidos aos exames geral e específico, escritos e orais, de avaliação de conhecimentos linguísitcos e de cultura geral.

A primeira reforma curricular, através da Portaria n. ${ }^{\circ}$ 253/96/M, altera os planos de estudos e a organização científico-pedagógica do curso de bacharelato, aprovados em 1994, porque existe “(...) conveniência em os adequar às necessidades atuais do mercado profissional" e para "(...) habilitar os seus graduados para um desempenho cada vez mais eficaz na sua vida profissional” (ibidem). 
Quadro 6 - Alterações: Bacharelato em Tradução/Interpretação Chinês/Português (Sistema de Ensino Português)

\begin{tabular}{|c|c|c|c|c|}
\hline & Disciplinas & Tipo & Créditos & $\begin{array}{l}\text { Horas/ } \\
\text { Sema- } \\
\text { nais }\end{array}$ \\
\hline 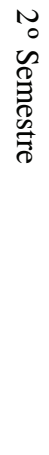 & $\begin{array}{l}\text { Metodologia e Teoria da Tradução e } \\
\text { da Interpretação I } \\
\text { Prática da Tradução } \\
\text { História de Macau e das Relações da } \\
\text { China com o Ocidente } \\
\text { Organização Política e Administrativa } \\
\text { de Macau e da China } \\
\text { Língua Chinesa II } \\
\text { Mandarim II } \\
\text { Português II } \\
\text { Métodos de Investigação } \\
\text { Iniciação à Documentação }\end{array}$ & $\begin{array}{l}\text { Anual } \\
\text { Anual } \\
\text { Anual } \\
\text { Anual } \\
\text { Anual } \\
\text { Anual } \\
\text { Anual } \\
\text { Sem. } \\
\text { Sem. }\end{array}$ & $\begin{array}{l}2 \\
6 \\
3 \\
3 \\
\\
4 \\
3 \\
3 \\
2 \\
2\end{array}$ & $\begin{array}{l}2 \\
6 \\
2 \\
3 \\
3 \\
4 \\
3 \\
3 \\
2 \\
2\end{array}$ \\
\hline 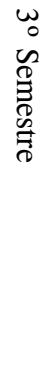 & $\begin{array}{l}\text { Metodologia e Teoria da Trad. e da } \\
\text { Int. II } \\
\text { Prática da Tr Especializada } \\
\text { Prática da Interpretação I } \\
\text { Introdução ao Estudo do Direito I } \\
\text { Sistema Jurídico de Macau I } \\
\text { Direito Chinês I } \\
\text { Estudos Económico-Financeiros } \\
\text { Língua Chinesa em Mandarim I } \\
\text { Português III }\end{array}$ & $\begin{array}{l}\text { Anual } \\
\text { Anual } \\
\text { Anual } \\
\text { Sem. } \\
\text { Sem. } \\
\text { Sem. } \\
\text { Sem. } \\
\text { Anual } \\
\text { Anual }\end{array}$ & $\begin{array}{l}2 \\
6 \\
6 \\
3 \\
3 \\
3 \\
3 \\
4 \\
2\end{array}$ & $\begin{array}{l}2 \\
6 \\
6 \\
6 \\
3 \\
3 \\
3 \\
3 \\
4 \\
2\end{array}$ \\
\hline
\end{tabular}

O novo plano começou a ser aplicado aos alunos que tinham iniciado o curso no ano letivo de 1996/97 e os restantes seguiram o plano anterior. A maior parte das disciplinas passam de semestrais a anuais e, pela primeira vez, são incluídas as disciplinas de Metodologia da Tradução/Interpretação, Métodos de investigação e de Iniciação à Documentação. 
Quadro 7 - Alterações: Bacharelato em Tradução/Interpretação Chinês/Português (Sistemas de Ensino Chinês/Inglês)

\begin{tabular}{|c|c|c|c|c|}
\hline & Disciplinas & Tipo & Créditos & $\begin{array}{l}\text { Horas/ } \\
\text { Sema- } \\
\text { nais }\end{array}$ \\
\hline 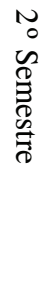 & $\begin{array}{l}\text { Língua Chinesa } \\
\text { Mandarim } \\
\text { Português I } \\
\text { História e Cultura Portuguesas } \\
\text { História e Cultura Chinesas } \\
\text { Introdução ao Processamento de } \\
\text { Texto } \\
\text { Processamento de texto avançado }\end{array}$ & $\begin{array}{l}\text { Anual } \\
\text { Anual } \\
\text { Anual } \\
\text { Anual } \\
\text { Anual } \\
\text { Sem. } \\
\text { Sem. }\end{array}$ & $\begin{array}{l}4 \\
4 \\
10 \\
3 \\
3 \\
2 \\
2\end{array}$ & $\begin{array}{l}4 \\
4 \\
10 \\
3 \\
3 \\
2 \\
2\end{array}$ \\
\hline 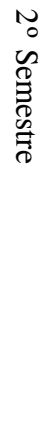 & $\begin{array}{l}\text { Metodologia e Teoria da Trad. e da } \\
\text { Int. I } \\
\text { Prática da Tradução } \\
\text { História de Macau e das Relações da } \\
\text { China com o Ocidente } \\
\text { Organização Política e Administrativa } \\
\text { de Macau e da China } \\
\text { Língua Chinesa em Mandarim I } \\
\text { Português II } \\
\text { Métodos de Investigação } \\
\text { Iniciação à Documentação }\end{array}$ & $\begin{array}{l}\text { Anual } \\
\text { Anual } \\
\text { Anual } \\
\text { Anual } \\
\text { Anual } \\
\text { Anual } \\
\text { Sem. } \\
\text { Sem. }\end{array}$ & $\begin{array}{l}2 \\
6 \\
3 \\
3 \\
\\
3 \\
7 \\
2 \\
2\end{array}$ & $\begin{array}{l}2 \\
6 \\
3 \\
3 \\
\\
3 \\
7 \\
2 \\
2\end{array}$ \\
\hline 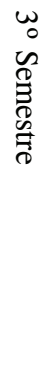 & $\begin{array}{l}\text { Metodologia e Teoria da Tradução e } \\
\text { da Interpretação II } \\
\text { Prática da Trad. Especializada I } \\
\text { Prática da Int. I } \\
\text { Introdução ao Estudo do Direito I } \\
\text { Sistema Jurídico de Macau I } \\
\text { Direito Chinês I } \\
\text { Estudos Económico-Financeiros } \\
\text { Língua Chinesa em Mandarim II } \\
\text { Português III }\end{array}$ & $\begin{array}{l}\text { Anual } \\
\text { Anual } \\
\text { Anual } \\
\text { Sem. } \\
\text { Sem. } \\
\text { Sem. } \\
\text { Sem. } \\
\text { Anual } \\
\text { Anual }\end{array}$ & $\begin{array}{l}2 \\
6 \\
6 \\
3 \\
3 \\
3 \\
3 \\
3 \\
2 \\
4\end{array}$ & $\begin{array}{l}2 \\
6 \\
6 \\
3 \\
3 \\
3 \\
3 \\
2 \\
4\end{array}$ \\
\hline
\end{tabular}

Prevê-se a realização de dois Projetos, em ambos os sistemas de ensino; no entanto, não está contemplada a realização de estágio 
profissional, perdendo-se, desta forma, a componente prática que até então tinha desempenhado um papel fundamental.

Ao publicar a Portaria n. ${ }^{\circ}$ 207/97/M, o Governo entende necessário “(...) consolidar e aprofundar as competências” adquiridas pelos detentores do grau de bacharel, "facultando-lhes a frequência de um curso complementar que lhes assegure formação com nível mais elevado de exigência científica" (ibidem).

Assim, é criado na Escola de Línguas e Tradução um ano complementar, conferente do grau de licenciatura, ao qual podem candidatar-se os detentores do grau de bacharel em Tradução/Interpretação do Instituto Politécnico.

Quadro 8 - Ano Complementar em Tradução/Interpretação - Chinês/Português

\begin{tabular}{|l|r|l|l|}
\hline Disciplinas & Tipo & Créditos & Horas/Semanais \\
\hline Técnicas da Tr Especializada* & 3 & 6 & $6 *$ \\
Técnicas de Interpretação* & 0 & $6 *$ \\
Tradutologia & & 2 & 2 \\
Direito Comparado & & 3 & 3 \\
Introdução às Ciências Sociais & 3 & 3 \\
Técnicas de Expressão da Língua & 2 & 2 \\
Chinesa & 2 & 2 \\
Técnicas de Expressão da Língua & & & \\
Portuguesa & & 24 \\
\hline Total de horas/semana: & & \\
\hline Total de horas semanais/ensino de línguas: & \\
\hline
\end{tabular}

* Possibilidade de opção por apenas uma destas disciplinas sendo, nesse caso, a carga horária semanal de 12 horas.

As disciplinas são anuais e distribuem-se por três áreas: Línguas, Tradução e Interpretação e Cultura. Assim, às línguas, Chinesa e Portuguesa, é atribuído o mesmo número de horas (apenas duas ho- 
ras semanais), levando-nos a depreender que o legislador considerava que, independentemente do sistema de ensino de proveniência, após a conclusão do bacharelato, os alunos já possuíam um bom domínio de ambas as línguas de trabalho, pelo que o currículo é aplicado a todos os alunos. Não dispondo de elementos que nos permitam tirar conclusões fundamentadas, parece-nos, contudo, que estamos perante uma tendência para uma especialização porque, por um lado, há uma forte presença da área do Direito, no bacharelato e no ano complementar, e, por outro lado, o aluno pode optar por Técnicas de Tradução Especializada ou Técnicas de Interpretação.

A partir desta altura, o Instituto Politécnico passa a oferecer um ensino bi-etápico, três anos (bacharelato) mais um (licenciatura), o que traz vantagens, visto que o currículo é estruturado de forma mais coesa e permite maior coordenação de conteúdos programáticos.

O ensino da Tradução foi sempre objeto de grande atenção, por parte dos responsáveis das políticas educativas, pelo que, em 2006, através do Despacho do SASC n. ${ }^{\circ} 86 / 2006$, o currículo do Curso de Bacharelato sofreu alterações, passando a designar-se "Curso de bacharelato em Tradução e Interpretação Chinês-Português".

Quadro 9 - Plano de Estudos do Curso de Bacharelato em Tradução/Interpretação Chinês/Português

\begin{tabular}{|c|c|c|c|c|}
\hline & Sistema de Ensino PT & $\begin{array}{l}\text { Sistema de Ensino CH } \\
\text { e ING }\end{array}$ & Créd & $\begin{array}{l}\text { Horas/ } \\
\text { Sem }\end{array}$ \\
\hline \multirow{7}{*}{$\begin{array}{l}\text { ॰ } \\
3 \\
z\end{array}$} & Chinês Elementar & Português I & $8 / 8$ & $8 / 8$ \\
\hline & Chinês Intermédio & Português II & $8 / 8$ & $8 / 8$ \\
\hline & Conversação em Chinês & Conversação em Por- & $2 / 3$ & $2 / 3$ \\
\hline & $\begin{array}{l}\text { Conversação em Chinês } \\
\text { Intermédio }\end{array}$ & $\begin{array}{l}\text { Conversação em Por- } \\
\text { tuguês II }\end{array}$ & $2 / 3$ & $2 / 3$ \\
\hline & $\begin{array}{l}\text { Leitura Intensiva em Portu- } \\
\text { guês I }\end{array}$ & Chinês -Mandarim I & $3 / 3$ & $3 / 3$ \\
\hline & $\begin{array}{l}\text { Leitura Intensiva em Portu- } \\
\text { guês II }\end{array}$ & Chinês -Mandarim II & $3 / 3$ & $3 / 3$ \\
\hline & $\begin{array}{l}\text { Introdução à Cultura } \\
\text { Chinesa }\end{array}$ & $\begin{array}{l}\text { Introdução à Cultura } \\
\text { Chinesa }\end{array}$ & $2 / 2$ & $2 / 2$ \\
\hline
\end{tabular}




\begin{tabular}{|c|c|c|c|c|}
\hline & $\begin{array}{l}\text { História Concisa de Macau } \\
\text { Processamento Informático } \\
\text { de Texto I } \\
\text { Processamento Informático } \\
\text { de Texto II } \\
\text { Leitura Chinesa* } \\
\text { Gramática da Língua Por- } \\
\text { tuguesa* }\end{array}$ & $\begin{array}{l}\text { História Concisa de } \\
\text { Macau } \\
\text { Proc. Informático de } \\
\text { Texto I } \\
\text { Proc. Informático de } \\
\text { Texto II } \\
\text { Chinês Moderno* } \\
\text { Gramática da Lingua } \\
\text { Port.* }\end{array}$ & $\begin{array}{l}2 / 2 \\
2 / 2 \\
3 / 2 \\
2 / 2\end{array}$ & $\begin{array}{l}2 / 2 \\
2 / 2 \\
6 / 4 \\
4 / 4\end{array}$ \\
\hline $\begin{array}{l}\text { No } \\
\text { D } \\
0\end{array}$ & $\begin{array}{l}\text { Chinês Avançado I } \\
\text { Chinês Avançado II } \\
\text { Conversação em CH Avan- } \\
\text { çado I } \\
\text { Conversação em CH Avan- } \\
\text { çado II } \\
\text { Leitura Intensiva em PT III } \\
\text { Leitura Intensiva em PT IV } \\
\text { Culturas dos Países Lusó- } \\
\text { fonos } \\
\text { Administração e FP da } \\
\text { China } \\
\text { Redação em PT* } \\
\text { Redação em Chinês* } \\
\text { Leitura Intensiva em Chi- } \\
\text { nês* }\end{array}$ & $\begin{array}{l}\text { Português III } \\
\text { Português IV } \\
\text { Compreensão e Ex- } \\
\text { pressão Oral de PT I } \\
\text { Compreensão e Ex- } \\
\text { pressão Oral de PT II } \\
\text { Sintaxe do Português } \\
\text { Redação em Português } \\
\text { Culturas dos Países } \\
\text { Lusófonos } \\
\text { Administração e FP da } \\
\text { China } \\
\text { Leitura de Textos de } \\
\text { Imprensa Port.* } \\
\text { Redação em Chinês* } \\
\text { Leitura Selecionada da } \\
\text { Literatura CH.* }\end{array}$ & $\begin{array}{l}6 / 6 \\
6 / 6 \\
2 / 2 \\
2 / 2 \\
4 / 3 \\
4 / 3 \\
2 / 2 \\
2 / 2 \\
2 / 2 \\
2 / 2 \\
2 / 3\end{array}$ & $\begin{array}{l}6 / 6 \\
6 / 6 \\
2 / 2 \\
2 / 2\end{array}$ \\
\hline $\begin{array}{l}\omega \\
0 \\
\vec{z}\end{array}$ & $\begin{array}{l}\text { Literatura Portuguesa } \\
\text { Literatura de Expressão } \\
\text { Lusófona } \\
\text { Redação de Documentos em } \\
\text { Port. } \\
\text { Intr. ao Estudo Económico- } \\
\text { Financeiro } \\
\text { Literatura Chinesa Contem- } \\
\text { porânea } \\
\text { Literatura Chinesa Moderna } \\
\text { Inglês I } \\
\text { Inglês II }\end{array}$ & $\begin{array}{l}\text { Literatura Portuguesa } \\
\text { Literatua de Expressão } \\
\text { Lusófona } \\
\text { Redação de Documen- } \\
\text { tos em Chinês } \\
\text { Intr. ao Estudo Econó- } \\
\text { mico-Financeiro } \\
\text { História e Cultura } \\
\text { Portuguesa } \\
\text { Literatura Chinesa } \\
\text { Moderna } \\
\text { Inglês I } \\
\text { Inglês II }\end{array}$ & $\begin{array}{l}3 / 3 \\
3 / 3 \\
2 / 3\end{array}$ & $\begin{array}{l}3 / 3 \\
3 / 3 \\
2 / 3\end{array}$ \\
\hline
\end{tabular}




\begin{tabular}{|l|l|l|l|l|}
\hline $\begin{array}{l}\text { Metodologia e Teoria da } \\
\text { Tradução* }\end{array}$ & $\begin{array}{l}\text { Metodologia e Teoria } \\
\text { da Tradução * } \\
\text { Metodologia e Técnicas de } \\
\begin{array}{l}\text { Interpretação. } * \\
\text { Redação de Documentos em écni- } \\
\text { Chinês* }\end{array}\end{array}$ & $\begin{array}{l}\text { cas de Interpretação* } \\
\text { Redação de Documen- } \\
\text { tos em Chinês* }\end{array}$ & $2 / 2$ & $8 / 4$ \\
\hline
\end{tabular}

*Disciplinas anuais.

Este novo plano de estudos é aplicado “(...) aos alunos que iniciem a frequência do curso no ano letivo de 2006/2007, devendo os restantes alunos concluir os seus estudos de acordo com o plano de estudos (...)" anterior.

Na opinião de Li (2008, s/ pág.), que subscrevemos,

[e]m comparação com o antigo plano de estudo, a nova organização científico-pedagógica do curso é mais abrangente e mais razoável, considerando as reais necessidades e interesses dos alunos de diferentes origens. O novo plano de estudo destaca tanto a área científica como a área profissional de Tradução/Interpretação chinês-português, e reajusta para 124 o número total de unidades de crédito necessário. Estamos convencidos de que, com a entrada em vigor do novo plano de estudos (...) os estudantes poderão adquirir mais conhecimentos acerca do seu futuro desempenho profissional (...).

A maior parte das disciplinas é semestral e todas são obrigatórias. Existe um conjunto de disciplinas que são comuns a todos os sistemas de ensino (frequentados no ensino secundário) e um paralelismo entre as restantes.

O ano complementar habilita com o grau de licenciatura e, até ao momento, é o último ciclo de ensino superior politécnico da Tradução/Interpretação - Chinês-Português.

Parece evidente que o ensino/aprendizagem das línguas de trabalho esteve presente na mente dos decisores que elaboraram 
e aprovaram o Plano de Estudos o que, em nosso entender, se deve à constatação da "fragilidade" a nível de domínio linguístico-comunicativo dos alunos que ingressam no Curso Complementar; considerando que a Gramática pertence à área das Línguas, o número de horas dedicado ao estudo das línguas de trabalho é de 24 , enquanto para as restantes disciplinas, inclusive a Prática, é de 21 horas semanais.

Embora sejam propostos dois ciclos de estudos, a experiência mostra que, salvo raríssimas exceções, os bacharéis ingressam, de imediato e sem terem tido uma experiência profissional, no Ano Complementar, para obterem o grau de licenciatura.

Não existe neste plano nenhuma vertente de especialização nem de separação entre a área da Tradução e da Interpretação, sendo ambas as componentes contempladas, desde as primeiras propostas curriculares até às atuais. De assinalar que, em consonância com as políticas governamentais, Macau, como plataforma entre a China e os Países Lusófonos, tem interesse num plano de estudos que promova o conhecimento da cultura e da literatura lusófonas.

A última reforma deu-se em 2010, através do Despacho do SASC n. ${ }^{\circ}$ 138/2010, não se tendo verificado alterações curriculares de destaque, mas passando a existir um único ciclo de estudos, de quatro anos, conferindo o grau de licenciatura.

O currículo é diferenciado conforme o sistema de ensino previamente frequentado, todas as disciplinas são semestrais e estão organizadas em obrigatórias e opcionais, tendo o aluno que concluir 166 unidades de crédito, para obter o referido grau.

\section{Conclusão}

O ensino superior politécnico da Tradução que “(...) nasceu de uma necessidade, acabou por se tornar para todos um imperativo. ${ }^{3}$ "tem assumido um papel muito importante tanto a nível da difusão das línguas como da formação de Intérpretes/Tradutores. 
Face aos condicionalismos da diminuta extensão territorial e, consequentemente, da estrutura da população de Macau, os Cursos, em Língua veicular Portuguesa, tendo como destinatários os residentes de Macau, tendem a enfrentar problemas na seleção de candidatos com um domínio e conhecimentos linguísticos e científicos que permitam assegurar a oferta e a qualidade dos mesmos, o que nos leva a defender a necessidade da criação de, por exemplo, um "ano zero" dedicado apenas ao estudo da Língua e da Cultura portuguesas.

Relativamente ao Instituto Politécnico de Macau, tanto os discursos políticos como a prática têm vindo a mostrar uma aposta no ensino da Tradução e nunca se verificou uma interrupção na oferta do curso, mesmo que, em alguns anos, o número de candidatos tenha sido exíguo. Neste aspeto, temos que reconhecer o esforço e o empenho do Instituto Politécnico de Macau que, ultrapassando todas as práticas economicistas de contenção de custo de funcionamento, tem feito uma forte aposta na formação de tradutores, correspondendo às necessidades do mercado.

O Português, para além do seu estatuto de língua oficial, até 2049, beneficia da estratégia de desenvolvimento, fortemente apoiada pelo Governo Central da República Popular da China, que consiste no fortalecimento de laços com a União Europeia e com os países Lusófonos (Bray, 2002). Urge, pois, apoiar o seu ensino, dentro dos parâmetros da maior qualidade.

A nível de tendências futuras, tudo leva a crer que a aposta no recrutamento de alunos do Continente Chinês irá continuar a ter sucesso, prevendo-se um aumento da "procura" da área da Tradução, o que, para os candidatos locais, poderá levar à necessidade de saberem dar resposta à concorrência desses alunos, almejando também para si formações de qualidade. Consideramos, em conformidade, importante definir um curriculum flexível, que contemple os perfis de entrada de públicos distintos, oriundos de sistemas de ensino diferentes, mas que pugnem ambos por uma preparação e uma qualificação de excelência, o que constituirá, certamente, uma vantagem 
e uma fonte de dinamismo e de afirmação do Instituto Politécnico como centro de formação superior em Línguas e Tradução.

Acresce relembrar que a cooperação com o exterior, nomeadamente com Portugal, irá sedimentar-se e outras parcerias estão a ser estabelecidas (e deverão continuar a sê-lo), de forma a consolidar e desenvolver o ensino politécnico da Tradução.

Estas novas tendências podem ser uma oportunidade de melhorar e melhor adequar a formação, encarada sempre no seu contexto real e tendo em conta, por um lado, as aspirações dos futuros profissionais e, por outro, as necessidades do mercado de trabalho.

O momento é propício para a afirmação da Língua Portuguesa na Ásia e, neste contexto, na Conferência Política Consultiva do Povo Chinês de 2012, os deputados de Macau apresentaram uma proposta de criação de um Centro de Língua Portuguesa em Macau, o que constitui um desafio para todas as instituições de ensino, nomeadamente, as de ensino superior e nos leva a concluir que o ensino superior da Tradução continuará a cimentar-se, de modo marcante, na Região Administrativa Especial de Macau.

\section{Notas}

1. Os alunos provenientes do sistema de ensino Inglês e Chinês são integrados no mesmo plano de estudos e os do sistema de ensino Luso-Chinês podem integrar uma ou outra, dependendo da secção frequentada.

2. O mesmo movimento de academização se passa com o corpo docente e, aos poucos, os profissionais da Tradução/Interpretação foram sendo substituídos por académicos na sua grande maioria sem prática de Tradução e/ou Interpretação; no entanto, é de assinalar que o Instituto Politécnico tem vindo a recrutar docentes bilingues e com experiência de tradução . 
3. LEI, Heong Iok, s/d, Prefácio, Boletim Informativo, Edição Especial, Escola Superior de Línguas e Tradução - 100 anos do curso de formação de intérpretes-tradutores, publicado pelo IPM, p.1.

\section{Referências}

Alves, J. M. (2003). A Administração Portuguesa de Macau e a Língua Chinesa: Relatório da Comissão para a Implementação da Língua Chinesa - Documentação Complementar - 1985-1986. Macau: Coord. e Edição de João C. Reis.

Boletim Oficial do Governo da Região Administrativa Especial de Macau [Em linha]. Disponível em: <http://pt.io.gov.mo/BO/Default.aspx > . Acesso em 2003-2009.

Lei, H. I. (s/d). Prefácio do Boletim Informativo, Edição Especial, Escola Superior de Línguas e Tradução "100 anos do Curso de Formação de Intérpretes/ Tradutores". Macau: IPM.

Li, C. (2008). Português Ensinado. Revista Macau, IV Série, no. 10. [Em linha]. Disponível em < http://www.revistamacau.com/rm.asp?id=012052. Acesso em 20-03-2009.

Santos, D. M. G. (1994). Macau-Primeira Universidade Ocidental do Extremo-Oriente. Macau: Fundação Macau e Universidade de Macau.

\section{LEGISLAÇÃO REFERENCIADA}

Decreto-Lei no 47/76/M - BO N. ${ }^{\circ} / 1976$ - I Série, p.1423, 1976.10.30

Decreto-Lei n. ${ }^{0} 11 / 80 / \mathrm{M}$ - BO N. ${ }^{\circ} 21 / 1980$ - I Série, p.1423, 1980.05.24

Decreto-Lei ${ }^{\circ} 16 / 92 / M-B O ~ N .{ }^{\circ}$ 9/1992 - I Série, p.838, 1992. 03.02

Despacho $n^{\circ}$ 86/SASC/06 - BO N. ${ }^{\circ} 32 / 2006$ - I Série, p. 1185-1189, 2006.09.18 
Despacho do SASC n. ${ }^{\circ}$ 138/2010 - BO N. ${ }^{\circ}$ 39/2010 - I Série, p. 839-844, 2010.09.27

Portaria $\mathrm{n}^{0}$ 183/86/M - BO N. ${ }^{\circ} 52$ /1986 - I Série, p. 3423, 1986.12.29

Portaria no $^{\circ}$ 272/93/M - BO N. ${ }^{\circ}$ 40/1993 - I Série, p.4124, 1993. 10.04

Portaria 100/94/M - BO N. ${ }^{\circ}$ 16/1994 - I Série, p.361, 1994. 04.18

Portaria n ${ }^{0} 89 / 95 / \mathrm{M}$ - BO N. ${ }^{\circ}$ 12/1995 - I Série, p.425, 1995. 03.20

Portaria n. ${ }^{\circ}$ 253/96/M - BO N. ${ }^{\circ}$ 42/1996 - I Série, p.2361, 1996. 10.14

Portaria n. ${ }^{\circ}$ 207/97/M - BO N. ${ }^{\circ}$ 36/1997 - I Série, p.1025, 1997.09.08

Recebido em 19/04/2012

Aceito em 30/08/2012 